\title{
MODEL TRANFORMASI MAINAN WARAK NGENDOG SEBAGAI UPAYA PELESTARIAN BUDAYA MAINAN TRADISIONAL KOTA SEMARANG
}

\author{
Abi Senoprabowo ${ }^{1}$, Khamadi ${ }^{2}$ \\ 1,2Program Studi Desain Komunikasi Visual \\ Fakultas Ilmu Komputer, Universitas Dian Nuswantoro \\ abiseno.p@gmail.com ${ }^{1}$, khamadi@dsn.dinus.ac.id ${ }^{2}$
}

\begin{abstract}
Abstrak
Mainan Warak Ngendog merupakan media pembelajaran orang tua kepada anak agar mereka menjaga mainan tersebut dengan cara menjalankan ibadah puasa dengan baik sehingga mendapat endog (telur). Namun, anak-anak sekarang lebih mengemari karakter-karakter seperti Doraemon dan Upin ipin yang tercermin pada jenis mainan yang dijual pada saat Dugderan. Hal ini membuat mainan Warak Ngendog semakin tergeser dan mulai dilupakan padahal di dalamnya terdapat nilai budaya, nilai moral, dan nilai keterampilan yang dapat membantu perkembangan sosial dan kecerdasan motorik, afektif serta kognitif anak. Mainan tradisional agar tetap lestari harus mampu mengikuti perkembangan zaman. Sehingga dengan memanfaatkan perkembangan IPTEK saat ini, mainan Warak Ngendog dapat ditransformasikan ke dalam bentuk mainan yang modern dengan tetap mempertahankan nilai budaya tradisinya. Penelitian ini mengusulkan tranformasi mainan tradisional Warak Ngendog melalui metode ATUMICS. Metode ATUMICS menganalisis elemen budaya menurut teknik (technique), kegunaan (utility), materi (material), ikon (icon), konsep (concept), dan bentuknya (shape). Sesuai prinsip seleksi dalam proses transformasi, elemen budaya yang dapat dipertahankan akan dipadukan dengan unsur mainan saat ini yang lebih menarik bagi anak-anak. Sebagai hasil akhirnya didapatkan model mainan modern hasil transformasi mainan tradisional Warak Ngendog seperti mainan berbentuk action figure, model kit, hingga aplikasi game.
\end{abstract}

Kata kunci: budaya, mainan, transformasi, Warak Ngendog.

\begin{abstract}
Warak Ngendog toy is a learning media for children to carry out fast so they get endog (eggs). However, children are now more interested in characters like Doraemon and Upin Ipin which are seen in the kinds of toys sold at Dugderan. This makes Warak Ngendog toy increasingly shifted and forgotten. Whereas, there are cultural values, moral values, and skill values that can help social development and motoric, affective and cognitive intelligence of children. Traditional toys to stay sustainable must be able to keep up with the times. By utilizing the development of science and technology today, Warak Ngendog toy can be transformed into a modern toy form while maintaining its traditional cultural value. This research proposes the transformation of Warak Ngendog toy through the ATUMICS method. The ATUMICS method analyzes cultural elements according to technique, utility, material, icon, concept, and shape. In accordance with the principle of selection in the transformation process, cultural elements that can be maintained will be combined with elements of toys that are more attractive to children today. As a result, there are several modern toy models that have been transformed by the traditional Warak Ngendog toy like the action figure, model kit, and game application.
\end{abstract}

Keyword: culture, toys, transformation, Warak Ngendog. 


\section{PENDAHULUAN}

Warak Ngendog merupakan binatang rekaan khas kota Semarang. Hampir setiap bangsa di dunia memiliki ikon atau simbol yang merepresentasikan karakter orang atau bangsa itu dalam bentuk hewan tertentu. Seperti Bangsa Aztec, Inca, dan Maya di benua Amerika memiliki Bison sebagai lambang kekuatan. Bangsa China memiliki karakter Naga dan Burung Hong. Bangsa Mesir memiliki Spinx. Sedangkan bangsa Inggris dan sejumlah negara Eropa lainnya menganggap singa sebagai simbol keberanian, kekuasaan, dan keunggulan ras mereka. Warak Ngendog merupakan binatang imajiner yang berwujud gabungan beberapa binatang sebagai simbol persatuan dari berbagai golongan etnis di Semarang yaitu Cina, Arab dan Jawa. Binatang ini memiliki nilai spiritual dan nilai filosofis yang diwujudkan dalam bentuk dan cara memainkanya. Bentuk Warak Ngendog (Senoprabowo, 2013) adalah kepalanya menyerupai kepala naga (Cina), tubuhnya layaknya buraq (Arab), dan empat kakinya menyerupai kaki kambing (Jawa). Binatang ini muncul pada saat acara Dugderan yaitu sebuah acara ritual menyambut awal Ramadhan (Triyanto, Rokhmat, \& Triyanto, 2013).

Ukuran Warak Ngendog ada dalam dua versi. Versi yang besar digunakan untuk arakarakan, sedang versi kecil digunakan untuk mainan anak-anak. Warak Ngendog dalam versi kecil ini, dijajakan oleh pedagang pada saat dugderan. Mainan ini dibeli oleh masyarakat karena makna filosofi dari Warak Ngendog. Anak-anak selalu diberi pesan pada orang tua mereka bahwa apabila mereka dapat menjaga mainan Warak Ngendog tersebut melalui berpuasa di bulan Ramadhan, maka mereka akan mendapatkan telur Warak Ngendog yang disimbolkan sebagai kemuliaan. Dahulu Warak Ngendog menjadi mainan yang sangat digemari warga Semarang. Pada waktu sebelum puasa, anak-anak diajak orang tuanya untuk mengunjungi acara Dugderan untuk membeli mainan Warak Ngendog. Mainan Warak Ngendog merupakan media pembelajaran orang tua kepada anak-anak agar mereka menjaga mainan tersebut dengan cara menjalankan ibadah puasa dengan baik agar mendapat endog (telur). Telur Warak Ngendog adalah perwujudan dari pahala ibadah puasa.

Dahulu disetiap acara Dugderan, mainan Warak Ngendog menjadi mainan yang wajib dimiliki oleh anak-anak Semarang, namun sekarang mulai ditinggalkan. Anak-anak sekarang lebih mengemari karakter-karakter dari luar negeri semacam Marsha \& The Bear, Shiva, Doraemon, dan Upin ipin yang tercermin pada jenis-jenis mainan yang dijual pada saat Dugderan. Akibat yang ditimbulkan maianan Warak Ngendog mulai disisihkan dari dagangan karena kurang laku dan dicari pengunjung Dugderan (Wicaksono \& Royanto, 2017).

Dengan adanya fenomena ini, maka perlu adanya suatu revitalisasi mainan Warak Ngendog sebagai mainan binatang imajiner khas Kota Semarang agar bisa diterima masyarakat Semarang, khususnya anak-anak. Proses revitalisasi diharapkan membuat karakter Warak Ngendog menjadi kuat dan impresif. Pendekatan yang digunakan adalah teori kognitif psikologi perkembangan, Piaget dalam Santrock (2003) berpendapat bahwa anak-anak menyesuaikan pemikiran mereka untuk menguasai 
gagasan-gagasan baru, karena informasi tambahan akan menambah pemahaman mereka terhadap dunia baru. Adanya interaksi antara anak-anak dengan Warak Ngendog akan membuat psikologi kognitif anak terhadap Warak Ngendog berkembang.

Masyarakat Indonesia sering kali terjebak dalam persoalan-persoalan kearifan lokal yang tersisihkan oleh modernitas. Masyarakat sedang dihadapkan pada persoalan sederhana, yaitu memilih menjadi tradisional atau menjadi modern (Hardiman, 2003). Kemajuan pesat globalisasi di era sekarang ini mempunyai dampak pada berbagai aspek kehidupan, tidak terkecuali untuk kehidupan anak-anak Indonesia. Arus modernisasi membuat mereka tidak lagi mengenal mainan tradisional yang merupakan warisan budaya bangsa (Nurjanah, 2012). Hal ini membuat mainan tradisional semakin tergeser dan mulai dilupakan padahal di dalamnya terdapat nilai budaya, nilai moral, dan nilai keterampilan yang dapat membantu perkembangan sosial dan kecerdasan motorik, afektif serta kognitif anak (Nugrahastuti, Pupitaningtyas, Puspitasari, \& Salimi, 2016).

Upaya pelestarian tidak sebatas menjaga mainan tradisional tetap ada, tetapi juga dapat berkembang sesuai dengan perkembangan jaman (Sujarno, 2011). Oleh karena itu, transformasi mainan Warak Ngendog ini akan merepresentasikan budaya Cina, Jawa dan Islam sebagai nilai akar dari mainan ini. Mainan Warak Ngendog ini juga akan tetap mempunyai nilai spriritual dan filosofi yang ada sebelumnya. Nilai-nilai ini ditransformasikan ke dalam bentuk modern sehingga tetap lestari di era modern. Metode yang digunakan dalam penelitian ini adalah metode transformasi budaya tradisi ATUMICS yaitu metode transformasi budaya dari tradisional ke bentuk lain sesuai perkembangan jaman untuk mengembangkan budaya tradisi (Nugraha, 2012). Sehingga dengan memanfaatkan perkembangan IPTEK saat ini, mainan Warak Ngendog dirasa dapat diadaptasikan ke dalam bentuk mainan yang lebih modern sehingga dapat kembali digemari anak.

\section{METODE PENELITIAN}

Penelitian ini menggunakan metode deskriptif kualitatif yaitu suatu metode yang digunakan untuk menggambarkan atau menganalisis suatu hasil penelitian tetapi tidak hanya untuk menjelaskan secara menyeluruh masalah yang akan diteliti dan diamati saja, namun juga ada tujuan lainnya (Sugiyono, 2012). Melalui metode tersebut dipaparkan fakta, keadaan, dan fenomena budaya mainan tradisional Warak Ngendog saat ini. Pertimbangan penggunaan pendekatan ini adalah: (1) data yang diambil bersifat alamiah atau wajar dengan konteks utuh (holistik), (2) Instrumen penelitian baik peneliti dan sumber data berupa manusia (human instrument), (3) metode pengumpulan data observasi dan wawancara sebagai metode utama, (4) analisis data dilakukan secara induktif dengan pendekatan teori-teori yang mendekati permasalahannya, dan (5) penelitian dibatasi oleh fokus sehingga penelitian menjadi lebih terarah (Suyanto \& Sutinah, 2013). Fokus dalam penelitian ini adalah mengidentifikasi elemen-elemen budaya tradisi dalam mainan Warak Ngendog di 
Semarang yang dapat ditransformasikan ke dalam sebuah perancangan mainan yang lebih modern.

Lokasi penelitian ini dilakukan di dua lokasi yaitu di kampung Purwodinatan dan di acara Dugderan di sekitar Pasar johar. Lokasi penelitian pertama yaitu kampung Purwodinatan, kecamatan Semarang Tengah, kota Semarang sebagai lokasi sentra pengrajin mainan Warak Ngendog. Lokasi kedua penelitian yaitu pada saat acara Dugderan yaitu di Sekitar Pasar Johar Kota Semarang. Acara Dugderan ini dilaksanakan menjelang Bulan Ramadhan dimana banyak mainan Warak Ngendog diperjualbelikan.

Selanjutnya dilakukan analisis data dilanjutkan pada tahap adaptasi dengan menggunakan metode ATUMICS. Nugraha (2012) menyebutkan bahwa melestarikan budaya tradisi dapat dilakukan dengan mentransformasikan budaya tradisi ke dalam budaya modern. Salah satunya adalah dengan metode ATUMICS (akronim dari kata Artefact, Technique, Utility, Material, Icon, Concept, dan Shape). Metode ini digunakan untuk mengkombinasikan beberapa elemen budaya tradisi dengan beberapa elemen budaya modern pada sebuah desain produk.

\section{HASIL DAN PEMBAHASAN}

\subsection{Warak Ngendog Sebagai Ikon Budaya Semarang}

Warak Ngendog merupakan kreativitas budaya lokal yang menjadi maskot dalam tradisi ritual Dugderan. Warak Ngendog dijadikan sebagai salah satu unsur dari tradisi arak-arakan ritual Dugderan ini merupakan warisan sejarah dan budaya masyarakat Semarang. Tradisi ini diselenggarakan rutin setiap tahun menjelang bulan Ramadhan. Secara turun temurun, prosesi maupun nilai-nilai yang ada berusaha dipertahankan oleh masyarakat Semarang. Pemerintah Kota Semarang mengemas penyelenggaraan Dugderan dalam bentuk festival, pasar rakyat, dan prosesi ritual yang melibatkan tokoh-tokoh agama dan pejabat kota Semarang maupun propinsi Jawa Tengah.

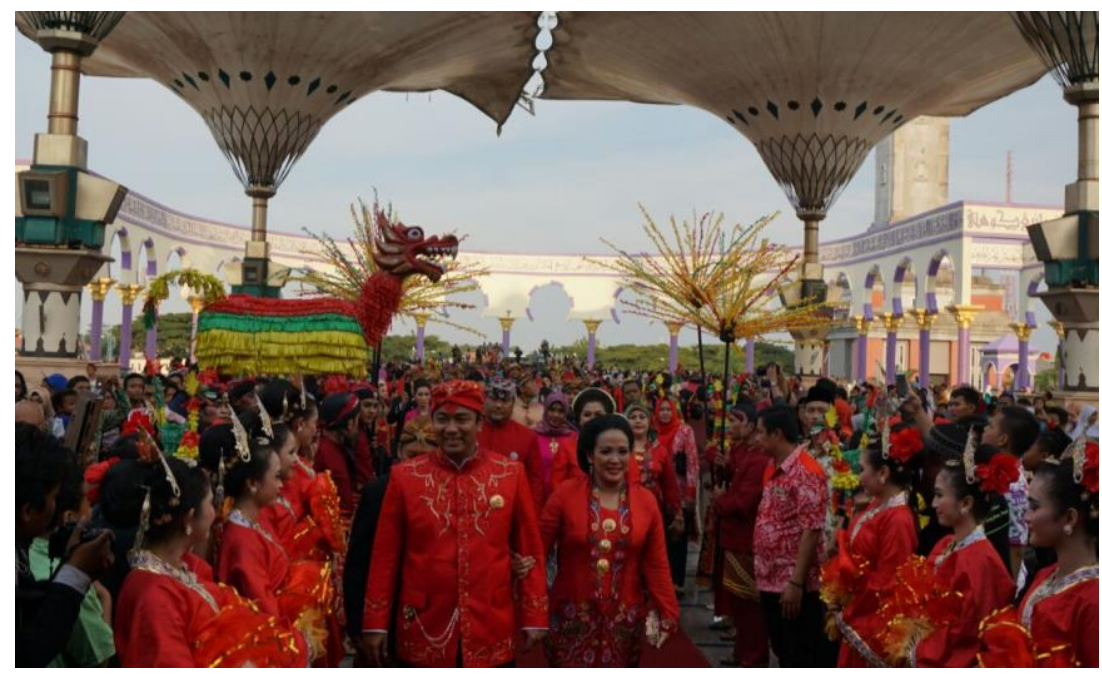

Gambar 1. Prosesi Ritual Dugderan di Masjid Agung Semarang [Sumber: Dokumentasi Deddy Award, 2018] 
Warak Ngendog dan tradisi ritual Dugderan adalah satu kesatuan. Menurut akumulasi pendapat Jawahir Muhamad, KH Hanief Ismail, dan analogi penulis, keduanya diciptakan bersamaan ketika ritual Dugderan pertama kali digagas dan dilaksanakan. Ritual Dugderan merupakan proses yang sudah disepakati susunan kegiatannya. Susunan acaranya cenderung seremonial dan kaku, meskipun suasananya dibuat penuh keakraban dari awal sampai menjelang pembacaan pengumuman awal puasa. Suasana menjadi hening dan penuh perhatian ketika Sang Bupati didampingi sejumlah tokoh dan ulama membacakan isi pengumuman. Begitu usai membaca, Sang Bupati memukul bedug. Dari acara inilah suasana kaku mulai mencair. Puncak kemeriahan ritual Dugderan ketika disulutnya meriam sampai 17 kali. Suara menjadi hingar bingar dan masyarakat menjadi gembira. Di antara hingar bingarnya suara meriam, dikeluarkan sebuah karya fenomenal dan menarik perhatian berupa seekor binatang rekaan yang selanjutnya disebut Warak Ngendog.

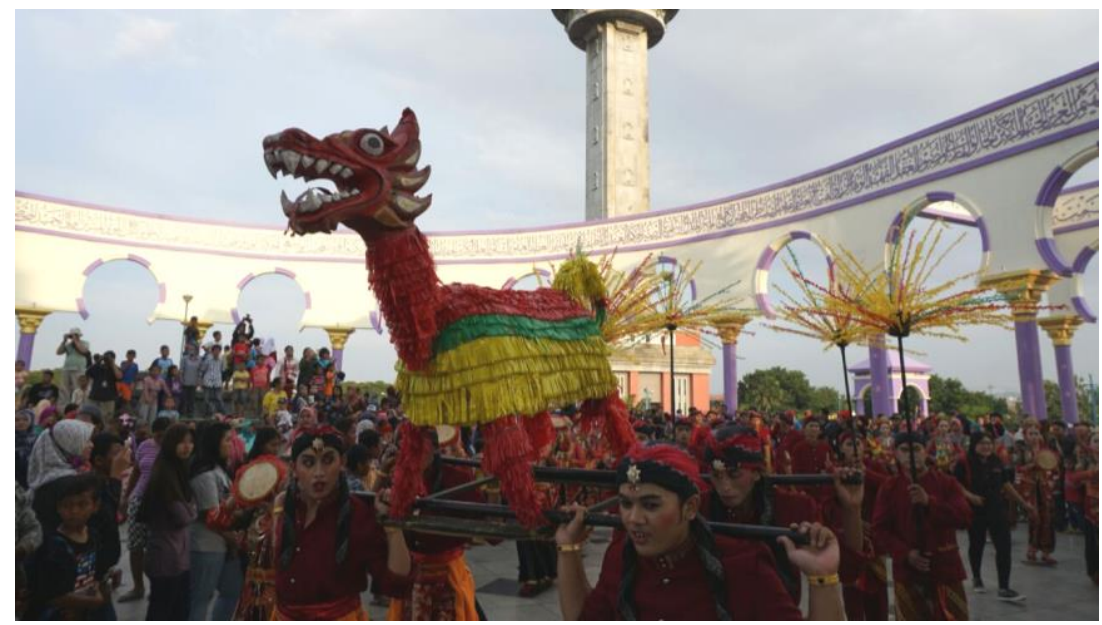

Gambar 2 Warak Ngendog untuk diarak [Sumber: Dokumentasi Deddy Award, 2018]

Masyarakat yang merapat ke tempat ritual Dugderan sangat leluasa menyaksikan atraksi dikeluarkannya Warak Ngendog. Sementara yang ada di kejauhan tidak dapat melihat ritual Dugderan dan menyimak isi pengumuman. Namun, ketika Warak Ngendog diarak di jalan-jalan kota masyarakat di penjuru Semarang sudah langsung tahu bahwa Dugderan telah selesai, awal puasa telah ditetapkan esok hari, dan ada pesan-pesan atau nasehat mulia lewat wujud binatang rekaan tersebut. Keterpaduan antara ritual Dugderan dan pengarakan Warak Ngendog, mensiratkan kesetaraan fungsi antara keduanya sebagai sarana pengumuman awal puasa dan pesan-pesan untuk diterapkan dalam berpuasa. Oleh sebab itu Warak Ngendog merupakan simbol yang penting dalam Dugderan. Karena bentuknya yang unik, kehadirannya sangat dinantikan sebagaimana masyarakat menantikan dilaksanakannnya ritual Dugderan.

Melihat kandungan makna pada karya Warak Ngendog tersebut, maka karya ini dijadikan sebagai ikon budaya kota Semarang oleh pemerintah kota Semarang (Supramono, 2007). Upaya ini terlihat dari penerapan Warak Ngendog pada beberapa logo acara yang digagas oleh Pemerintah Kota Semarang, serta dibangunnya monumen 
Warak Ngendog di Jalan Kaligawe Semarang. Namun sebagai ikon budaya, Warak Ngendog belum diketahui secara luas oleh masyarakat Semarang padahal Warak Ngendog sendiri sudah identik dengan warga Kota Semarang.

Warak Ngendog berasal dari perpaduan beberapa binatang simbol budaya yaitu Jawa, Cina dan Arab. Binatang itu berkepala "Kilin" sebagai binatang agung dan berpengaruh di Cina dengan badan "bouraq" sebagai binatang suci kendaraan Nabi Muhammad saat Isra' Mi'raj. Ada juga yang berpendapat bahwa warak berkepala Naga, binatang simbol milik orang Cina dengan kaki Kambing, binatang yang banyak dimiliki orang pribumi Jawa dan sering digunakan untuk berkurban saat Idul Adha. Perpaduan beberapa binatang simbol milik beberapa kelompok etnik masyarakat tersebut diharapkan diikuti dengan semakin eratnya persatuan orang Cina dengan orang Jawa atau umat Islam. Kemudian bentuk Warak Ngendog ada yang ditambahi dengan sebuah telur (dalam bahasa Jawa disebut Endog) di antara dua kaki belakangnya (Supramono, 2007). Dalam bentuk kecil atau mainan, telurnya merupakan telur ayam atau bebek asli yang sudah matang. Pemasangan telur asli pada mainan ini dimaksudkan agar anak merasa tertarik untuk memiliki dan memakannya sebagai hadiah kemauan mereka untuk ikut berlatih puasa. Karena biasa ditambahi atribut telur atau Endog tersebut, selanjutnya dikenal pula istilah Warak Ngendog.

Menurut Djawahir Muhammad dalam Supramono (2007), secara pakem beberapa bagian tubuh Warak Ngendog yang tangible mempresentasikan keterwakilan budaya Jawa, Cina dan budaya Islam yang profane, berwujud kind (benda) atau sesuatu yang berwujud atau dilakukan. Sedangkan dalam "roh" Warak Ngendog yang intangible tersimpan sesuatu yang sakral berupa mind yakni pikiran, akal budi atau nilai-nilai yang mulia, atau value.

a. Kepala, bagian tubuh yang paling hakiki/mulia (ontologism) mempresentasikan nilai budaya/kearifan lokal atau mewakili keberadaan etnis Jawa.

b. Leher, yang menjadi urat/dinamika kehidupan (epistemologis) mempresentasikan nilai budaya Islam atau mewakili keberadaan komunitas/etnis Arab.

c. Badan, yang menyangga unsur materi kehidupan (aksiologis) mempresentasikan nilai budaya timur (oriental) atau mewakili keberadaan etnis Tionghoa (Cina).

Tabel 1. Deskripsi Bentuk dan Makna Warak Ngendog [sumber: Supramono, 2007]

\begin{tabular}{|c|c|l|l|}
\hline No & Unsur & \multicolumn{1}{|c|}{ Deskripsi Bentuk } & \multicolumn{1}{|c|}{ Makna } \\
\hline 1 & Kepala & $\begin{array}{l}\text { Berupa kambing } \\
\text { a. Sudut lurus } \\
\text { b. Mata terbuka lebar } \\
\text { c. Mulut menyeringai, gigi } \\
\text { atas bawah lancip }\end{array}$ & $\begin{array}{l}\text { Kambing hewan untuk aqiqah } \\
\text { a. Jalan yang lurus } \\
\text { b. Untuk melihat yang baik } \\
\text { c. Uua buah tanduk tegak } \\
\text { e. Dua buah telinga tegak } \\
\text { bertujuan baik tajam tetapi } \\
\text { d. Istiqomah, konsisten } \\
\text { e. Mendengarkan segala hal yang } \\
\text { baik. }\end{array}$ \\
\hline
\end{tabular}




\begin{tabular}{|c|l|l|l|}
\hline 2 & Leher & $\begin{array}{l}\text { Lenjang, panjang, serupa } \\
\text { onta }\end{array}$ & $\begin{array}{l}\text { Bernafas panjang, berdaya tahan } \\
\text { hidup kuat/tinggi }\end{array}$ \\
\hline 3 & $\begin{array}{l}\text { Badan/ } \\
\text { perut }\end{array}$ & Sudut-sudutnya lurus & $\begin{array}{l}\text { Tempat menyimpan/ memproses } \\
\text { rizki yang baik dan halal }\end{array}$ \\
\hline 4 & Ekor & Lurus ke atas & Mengikuti tuntutan pimpinan \\
\hline 5 & Kaki & Empat kaki berdiri tegak & $\begin{array}{l}\text { Sifat-sifat orang terpercaya: Sidiq, } \\
\text { Amanah, Tabligh, Fathonah }\end{array}$ \\
\hline 6 & $\begin{array}{l}\text { Telur } \\
\text { warak }\end{array}$ & Bulat & $\begin{array}{l}\text { Pahala yang utuh dari perilaku yang } \\
\text { baik/ketakwaan }\end{array}$ \\
\hline 7 & Bulu & Keriting, ada "kendhit" & $\begin{array}{l}\text { Kambing yang bulu perutnya } \\
\text { memiliki bentuk kendhit atau } \\
\text { lingkaran bulu berwarna putih } \\
\text { dipercaya menyimbolkan nilai- nilai } \\
\text { kebaikan. }\end{array}$ \\
\hline
\end{tabular}

Sebagaimana yang diungkapkan oleh Triyanto (2013) secara sederhana bentuk Warak Ngendog dapat dikelompokkan menjadi tiga bentuk, yaitu struktur yang mengacu pada pakem (tradisional), modern, dan kontemporer. Pertama, bentuk Warak Ngendog tradisional yang mengacu pakem yaitu bentuk struktur dan atribut masih bersifat simbolik seperti penggambaran Warak Ngendog di tabel di atas. Kedua, bentuk Warak Ngendog modern terlihat secara struktur dan bentuk visualnya masih memiliki pakem atau simbolik namun terkadang sangat mengejar keindahan bentuk visualnya sehingga secara perlahan-lahan ada nilai-nilai simbolik yang mulai terabaikan. Ketiga, bentuk visual Warak Ngendog posmodern telah mengalami perubahan atau meninggalkan struktur dan atribut yang bersifat pakem. Struktur dan atribut sudah tidak memiliki nilai simbolik semua. Dalam upaya pelestarian mainan tradisional maka bentuk mainan Warak Ngendog sebagai hasil transformasi harus mengandung pakem yang memiliki nilai simbolik.

\subsection{Keberadaan Mainan Warak Ngendog Saat Ini}

Dalam ritual budaya Dugderan, dimeriahkan juga dengan mainan anak-anak yang disebut dengan Warak Ngendog (Hakim, 2012). Warak Ngendog sendiri terdapat dua versi yaitu versi besar yang digunakan untuk karnaval pada saat ritual Dugderan untuk menentukan awal puasa Ramadhan dan versi kecil yang dijual sebagai mainan yang dijual di Pasar Dugderan dan dapat dibeli oleh anak-anak sebagai mainan khas kota Semarang. Mainan Warak Ngendog yang ada terbagi kedalam dua versi, yaitu Warak Ngendog versi yang beroda dan versi yang tidak beroda. Warak Ngendog versi beroda dimainkan anak-anak dengan menariknya keliling kampung, sedang versi yang tak beroda hanya dipajang di lemari ruang tamu.

Bagi anak-anak momen Dugderan adalah momen yang sangat indah. Pada setiap acara Dugderan anak-anak diajak oleh orang tua mereka untuk mengunjungi pasar Dugderan. Para orang tua ingin membelikan mainan Warak Ngendog pada anak-anak mereka. Para orang tua sangat antusias membelikan mainan Dugderan agar anak 
mereka tidak malu pada teman-teman mereka. Menurut Ibu Sumiati, salah satu pengunjung pasar Dugderan 2018, mengatakan "ora Dugderan yen ora tuku dolanan", maksud dari perkataan tersebut adalah "bukan Dugderan jika tidak membeli mainan". Pernyataan ini seperti sudah melekat pada sebagian masyarakat Semarang yang masih mempertahankan tradisi Dugderan ini. Dari penyataan tersebut terlihat bahwa para orang tua di Semarang sangat menyadari pentingnya membahagiakan anak-anak mereka ketika momen Dugderan ini tiba dengan cara membelikan mainan Dugderan. Mereka tidak mau anak mereka malu karena tidak memiliki mainan Dugderan pada momen tersebut.

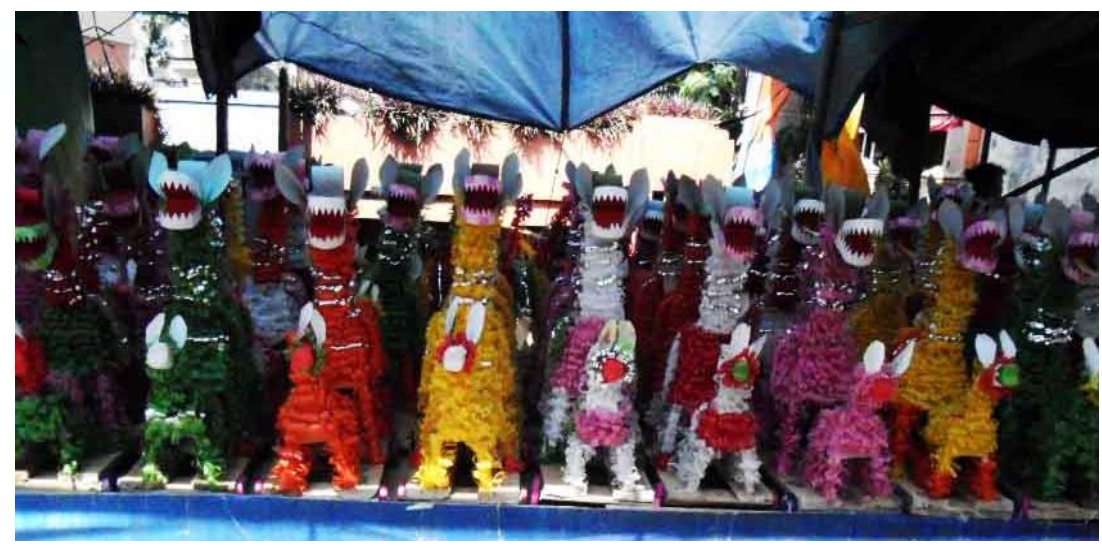

Gambar 3. Mainan Warak Ngendog di Lapak Penjual [Sumber : Dokumentasi Penulis]

Ibu Muniti dan Bapak Sukimin adalah pasangan suami istri yang merupakan salah satu pedagang di pasar Dugderan menuturkan bahwa mainan yang dijual dalam pasar Dugderan selain mainan Warak Ngendog adalah alat memasak dari tanah liat, kompor dari seng, panci dari seng, celengan dari tanah liat, dakon, perahu klotok, gangsing, dan lain sebagainya. Warak Ngendog menjadi mainan yang paling laris sejak mereka berjualan pada era tahun 80 -an. Warak Ngendog buatan mereka dibuat oleh pengrajin di daerah Abangan sebelah timur pasar Johar.

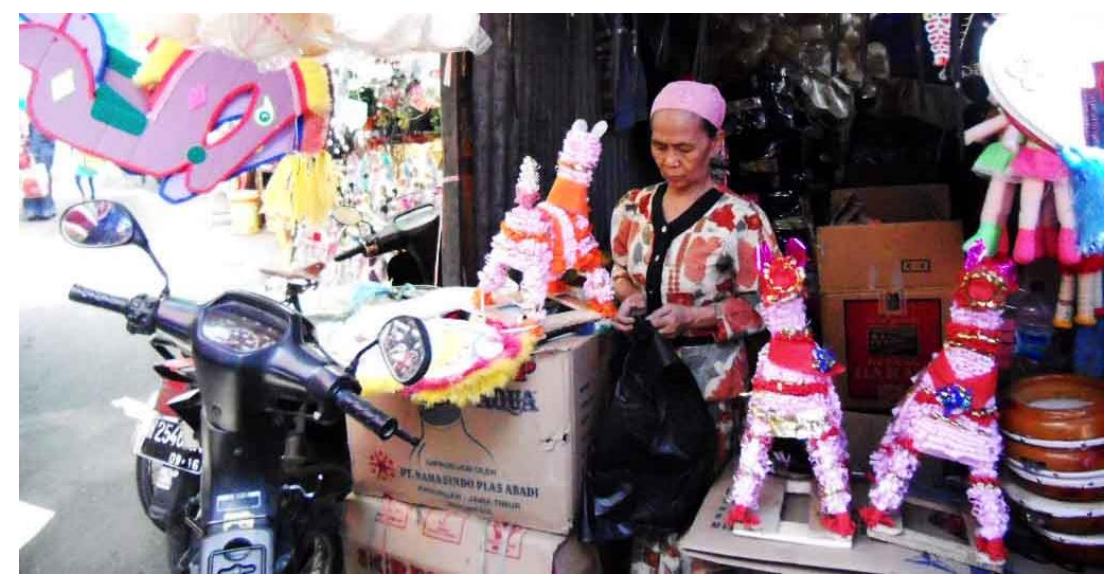

Gambar 4 Ibu Muniti, Salah Satu Penjual Warak Ngendog [sumber : Dokumentasi penulis] 
Warak Ngendog yang dijual di pasar Dugderan memang tidak sesuai pakem yang ada, tetapi tetap mempertahankan filosofi yang ada. Makna filosofi dari Warak Ngendog ini adalah anak-anak selalu diberi pesan pada orang tua mereka bahwa apabila mereka dapat menjaga mainan Warak Ngendog tersebut melalui berpuasa dan melakukan amalan-amalan di bulan Ramadhan, maka mereka akan mendapatkan telur Warak Ngendog yang disimbolkan sebagai kemuliaan. Jadi mainan Warak Ngendog hanya sebagai media untuk menumbuhkan nilai spiritualitas anak-anak kota Semarang agar mereka dapat menjalankan ibadah bulan Ramadhan dengan baik.

Bentuk mainan Warak Ngendog yang kurang sesuai pakem ini secara tidak langsung menghilangkan makna simbol yang ada di Warak Ngendog. Perubahan-perubahan bentuk yang bisa dilihat adalah hilangnya elemen telur Warak Ngendog, perubahan bentuk kepala menjadi kepala naga/barongsai, perubahan proporsi tubuh (leher dan kaki warak), dan perubahan garis/sudut lurus menjadi sudut garis lengkung. Perubahan bentuk tersebut tentu akan mempengaruhi apresiasi terhadap Warak Ngendog, diantaranya orang tidak dapat membedakan bentuk Warak Ngendog yang asli atau bentuk yang telah dimodifikasi sehingga orang tidak tahu makna, simbol, dan ikon yang benar. Warga masyarakat secara perlahan kehilangan rasa memiliki karena Warak Ngendog tidak lagi mempresentasikan nilai-nilai yang diwariskan. Hal ini dapat memancing timbulnya apatisme dan sentimen sosial (Djawahir Muhammad 2015: 9394).

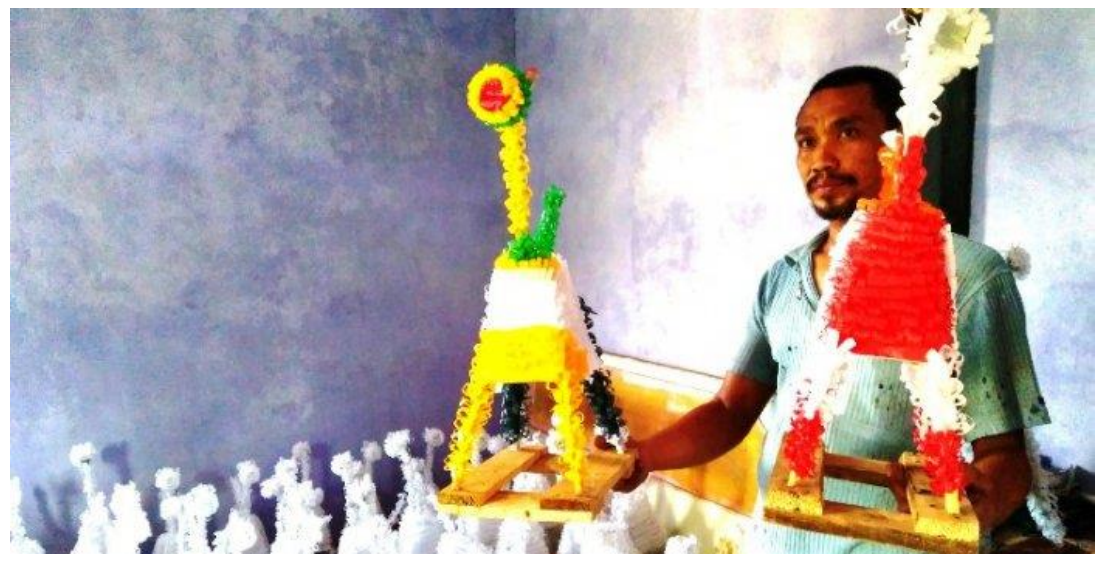

Gambar 5. Bapak Arif, Pengrajin Mainan Warak Ngendog [sumber : Susanto, 2017]

Pengrajin membuat mainan Warak Ngendog dengan memanfaatkan bahan-bahan yang mudah dijumpai seperti kayu bekas dan kertas minyak. Namun, bahan kayu kini mulai sulit didapat. Sementara harga kertas minyak yang menjadi bahan penutup tubuh Warak juga naik. Dikarenakan bahan baku mulai sulit dan mahal, para pengrajin memberikan harga per mainan Warak Ngendog hingga Rp 50.000,00. Meskipun harga tersebut tidak sebanding dengan kesulitan, waktu, dan kreatifitas pengrajin.

Berdasarkan paparan keberadaan mainan Warak Ngendog di atas menunjukkan bahwa Mainan Warak Ngendog yang diproduksi oleh pengrajin saat ini masih memepertahankan bentuk seperti pakem yang sudah ada dan masih menggunakan 
material yang sama juga. Mainan Warak Ngendog masih menggunakan rangka logam seng, menggunakan alas kayu, dan menggunakan kertas warna-warni untuk digunakan sebagai bulu di badannya. Pengunjung pasar Dugderan pada tahun 2018 yang berada di sekitar Pasar Johar Kota Semarang masih banyak. Pengunjung yang datang kebanyakan adalah orang tua beserta anaknya yang ingin membelikan mainan untuk anak mereka. Jenis mainan yang dijual di pasar Dugderan meliputi Warak Ngendog, alat memasak dari tanah liat, kompor dari seng, panci dari seng, celengan dari tanah liat, dakon, perahu klotok, gangsing. Mainan-mainan ini adalah mainan tradisional yang biasanya memang diperjualbelikan oleh para pedagang mainan di pasar Dugderan. Tetapi pedagang mainan juga menjual mainan-mainan yang lebih modern seperti robot-robotan, boneka kartun (shaun the sheep, angry bird), tembak-tembakan, bola, bahkan piranti seluler berbagai merek. Jumlah dagangan mainan tradisional lebih sedikit dibandingkan dengan mainan modern yang ada di pasar Dugderan tahun 2018. Menurut penuturan pedagang, hal ini disebabkan oleh karena bentuk yang menarik sehingga anak-anak sangat menyukainya. Selain itu harga produk yang lebih murah serta dapat dibuat dalam jumlah banyak, membuat mainan modern menjadi pilihan para pedagang untuk diperjualbelikan. Dengan harga produk yang murah dan dijual dalam jumlah banyak, akan membuat pendapatan dan laba mereka menjadi lebih banyak.

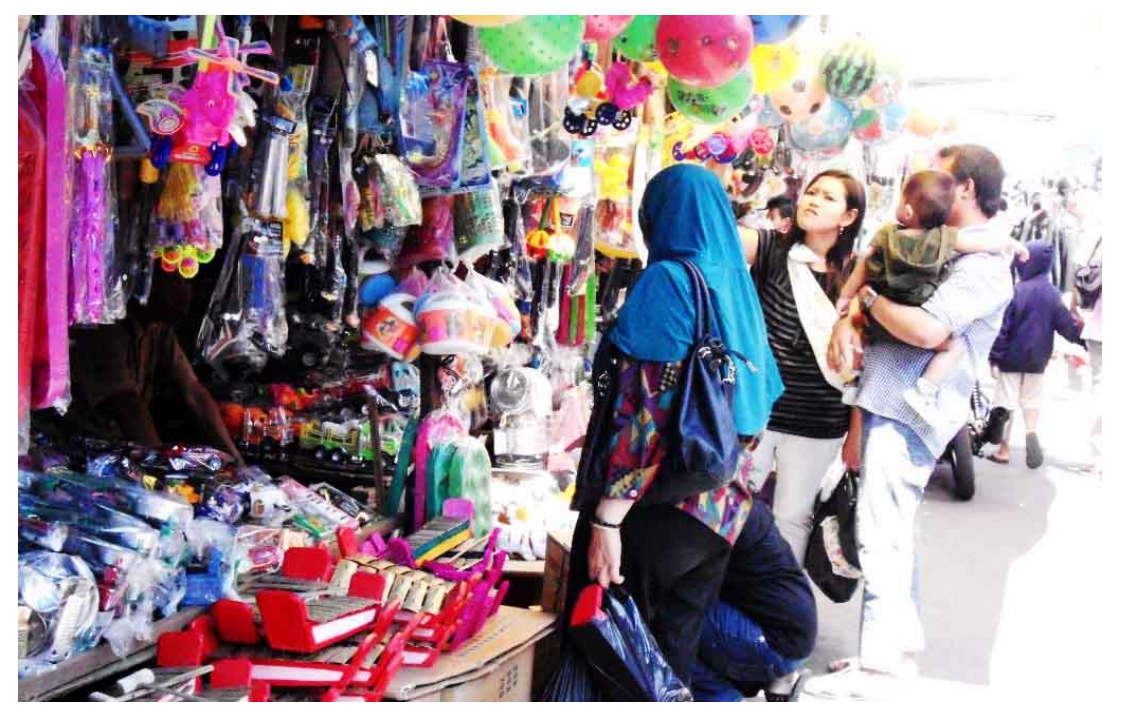

Gambar 6. Mainan Modern Lebih Dominan di Pasar Dugderan [sumber : dokumentasi penulis]

Mainan Warak Ngendog mulai dikesampingkan oleh pedagang di pasar Dugderan. Hal ini terlihat dari peletakan produk mainan yang dijual. Pedagang meletakkan mainan Warak Ngendog dibawah lapak dagangannya, sedangkan mainan modern diletakan di atas karena merupakan mainan yang lebih diminati pembeli. Selain itu, jumlah mainan Warak Ngendog yang terjual juga sangat sedikit yaitu tidak lebih dari 5 buah per hari. Jumlah orang tua yang membelikan mainan Warak Ngendog sangat sedikit. Hal ini disebabkan karena orang tua merasa mainan Warak Ngendog bentuknya tidak menarik dan tidak dapat bertahan lama. Selain itu, harga yang mahal juga menjadi faktor 
pertimbangan. Para orang tua lebih memilih mainan tradisional yang lainnya seperti alat memasak dari tanah liat (untuk perempuan) dan kapal Klotok (untuk laki-laki) yang memiliki harga lebih murah. Para orang tua juga tidak mengetahui makna filosofi dari mainan Warak Ngendog. Anak-anak sebenarnya menyukai Warak Ngendog yang mereka lihat pada saat karnaval ritual Dugderan. Tetapi mereka tidak menyukai mainan Warak Ngendog karena mereka lebih memilih mainan modern. Menurut mereka, mainan modern lebih bagus tampilan dan bentuknya dibanding mainan Warak Ngendog. Selain itu, mainan modern lebih menyenangkan dibandingkan mainan Warak Ngendog. Anak-anak juga tidak mengetahui makna filosofi dari mainan Warak Ngendog.

\subsection{Analisis Artefak Mainan Warak Ngendog}

Bentuk mainan Warak Ngendog yang banyak dijual oleh pedagang saat ini dapat dikategorikan bentuk Warak Ngendog yang modern yaitu bentuknya mengalami perubahan tetapi masih mengandung beberapa pakem yang dipertahankan. Oleh karena itu, dalam penelitian ini menggunakan mainan warak ngendog yang banyak beredar sebagai bahan analisis artefak dalam metode ATUMICS. Mainan Warak Ngendog sebagai artefak (Artefact) dianalisis menurut enam elemen dasarnya, yaitu teknik (Technique), kegunaan (Utility), bahan (Material), ikon (Icon), konsep (Concept), dan bentuk (Shape) sebagai berikut:

1. Technique

Secara teknik, mainan tradisional Warag Ngendog dapat dijabarkan sebagai berikut:

a) Teknik dan proses produksi; pembuatan mainan Warak Ngendog meliputi pembuatan kerangka anatomi mainan dengan kayu, pembungkusan seluruh kerangka dengan kertas tebal, pemasangan hiasan kertas warna-warni dengan menggunakan lem di permukaan luar mainan, pemberian empat roda pada bidang alas agar Warak Ngendog bisa dijalankan, dan finishing dengan pemberian telur dibagian tengah di antara kaki depan dan belakang.

b) Teknologi produksi; mainan warak Ngendog masih dibuat secara manual menggunakan tangan dan peralatan sederhana.

c) Peralatan (tool) yang digunakan untuk membuat mainan Warak Ngendog sangat sederhana tidak menggunakan mesin, yaitu seperti gergaji, palu, dan sebagainya.

d) Keahlian (skill); keahlian pengrajin menentukan bentuk mainan yang dihasilkan. Daya kreasi dan pemahaman esensi Warak Ngendog masing-masing pengrajin berbeda. Seringkali pengrajin mengejar visual tanpa memperhatikan esensi pakem Warak Ngendog sehingga mainan yang ada saat ini cenderung memiliki bentuk yang modern.

2. Utility

Utility memiliki beberapa maksud di antaranya sebagai berikut;

a) Fungsi; mainan Warak Ngendog pada dasarnya berfungsi sebagai media edukasi bagi anak tentang budaya Warak Ngendog dalam menumbuhkan nilai spiritualitas agar anak dapat menjalankan ibadah bulan Ramadhan dengan baik. 
b) Kegunaan; mainan Warak Ngendog berguna bagi anak sebagai mainan yang menghibur disamping melatih kecerdasan motorik anak dengan memainkannya. Mainan Warak Ngendog juga dapat digunakan sebagai benda hiasan.

\section{Material}

Bahan-bahan yang digunakan dalam pembuatan mainan Warak Ngendog secara umum menggunakan bahan yang sederhana dan mudah dijumpai. Bahan-bahan tersebut berupa kayu dan paku atau kawat besi untuk pembuatan rangka, kertas tebal atau karton atau kertas semen untuk pembungkusan kerangka, kertas-kertas yang agak tipis dan bewarna-warni seperti kertas doorslag dan kertas minyak untuk menghias badan mainan, roda mainan untuk roda di bagian alas, dan telur mainan sebagai endog. Namun saat ini bentuk mainan warak tidak dilengkapi roda, telur, dan tali untuk menarik mainan.

4. Icon

Mainan Warak Ngendog memiliki bentuk ikonik berupa hewan imajiner berkepala naga, berbadan buraq, dan berkaki kambing, serta memiliki telur. Mainan Warak Ngendog diwujudkan sesuai dengan maksud budaya Warak Ngendog yaitu perpaduan dari budaya etnis Cina, Arab, dan Jawa yang ada di Semarang. Hal ini juga tercermin dari warna yang digunakan yaitu merah melambangkan etnis cina, hijau melambangkan etnis arab, dan kuning melambangkan etnis jawa.

\section{Concept}

Konsep dari mainan warak Ngendog dapat dilihat dari fungsinya yaitu mainan yang bernilai religius untuk mengajarkan anak untuk menjaga amalan dalam beribadah puasa Ramadhan agar mendapatkan pahala dan kemuliaan yang disimbolkan dalam bentuk telur (endog). Konsep mainan Warak Ngendog juga tampak dari bentuk ikoniknya yaitu mainan yang melambangkan persatuan warga Semarang yang terdiri dari etnis Jawa, Arab, dan Cina.

\section{Shape}

Bentuk mainan Warak Ngendog yang ada saat ini termasuk jenis mainan tradisional. Unsur shape erat kaitannya dengan pakem bentuk budaya Warak Ngendog. Bentuk yang dimiliki oleh mainan Warak Ngendog saat ini bisa dikatakan tidak seluruhnya mempertahankan pakem budaya Warak Ngendog. Jika sesuai pakem bentuk Warak Ngendog seharusnya berstruktur lurus, tetapi mainan yang ada saat ini lebih ke bentuk yang lengkung. Proporsi mainan yang dibuat juga cenderung kurang proporsi dari konsep budaya Warak Ngendog. Hal ini dibuat agar bentuk mainan menjadi lebih estetis, tidak kaku, serta tergantung dari persepsi dan kreasi pengrajin mainan. Unsur visual yang menonjol di mainan Warak Ngendog adalah warna-warni permukaan mainan yaitu perpaduan merah, biru, kuning, hijau, dan putih.

Hasil analisis ini menjadi dasar dalam mengembangkan mainan Warak Ngendog dalam bentuk mainan yang lebih modern dan memiliki nilai edukasi sebagai bentuk pelestarian budaya mainan tradisional. 


\subsection{Model Transformasi Mainan Warak Ngendog}

Sebagaimana tujuan dari transformasi mainan Warak Ngendog ini adalah untuk melestarikan keberadaannya yang memiliki nilai budaya yang ikonik dan mendidik, maka bentuk transformasi yang dituju harus memperhatikan unsur-unsur mainan yang mendidik. Menurut Muliawan (2009), unsur mainan yang mendidik harus bisa memberikan rangsangan atau respon balik pada indra anak diantaranya unsur bentuk, materi bahan, suara, cahaya dan warna, gerak dan perubahan, aroma atau bau, unsur pengetahuan, pengalaman, dan imajinasi. Selanjutnya peneliti mengolah unsur-unsur tersebut dalam analisis aspek edukatif mainan Warak Ngendog untuk mendapatkan model transformasi mainan yang ideal, yaitu sebagai berikut;

1. Aspek Estetis

Aspek ini meliputi unsur bentuk yang secara visual menarik dan sederhana. Visual mainan yang memiliki unsur cahaya dan warna yang baik menjadi daya tarik dan baik bagi indera penglihatan anak. kesederhanaan bentuk mainan membuat anak lebih fokus karena bentuk mainan yang rumit cenderung menyulitkan dan tidak menarik bagi anak. Unsur visual mainan Warak Ngendog saat ini terlihat sudah baik yaitu mainannya penuh dengan warna sehingga sangat menarik untuk dilihat. Namun melihat unsur kesederhanaannya, mainan Warak Ngendog saat ini cenderung cukup kompleks bagi anak. Hal ini nampak dari detail yang ingin diperlihatkan tetapi menggunakan material yang beragam yang mengurangi nilai estetis mainan. Model transformasi pada aspek estetis ini adalah dengan mempertahankan unsur warna dan mengurangi kerumitan yang ada dalam mainan Warak Ngendog saat ini menjadi mainan yang sederhana dan menarik. Unsur kesederhanaan ini akan berpengaruh pada unsur technique pada pemetaan ATUMICS. Pembuatan mainan yang sederhana akan mengubah teknik dan proses produksi bahkan mengubah teknologi produksi yang semula manual ke produksi mesin. Hal ini ditunjang dengan ditemukannya teknologi-teknologi untuk menunjang hal tersebut seperti Printer 3D, Resin, Robot, dll.

\section{Aspek Ergonomi}

Aspek ini meliputi aspek keamanan dan kenyamanan penggunaan mainan oleh anak. Aspek keamanan terlihat dari pemilihan material bahan mainan yang aman bagi anak. Hal ini dirasa kurang diperhatikan pada mainan Warak Ngendog saat ini. Penggunaan bahan bertekstur keras seperti kayu dan paku membahayakan bagi anak. Mainan yang aman bagi anak biasanya juga disertai panduan penggunaan mainan. Aspek kenyamanan mainan dapat dilihat dari ukuran dan bentuk mainan. Ukuran yang proporsional dengan kebutuhan anak dan bentuk mainan yang praktis sehingga mudah dimainkan dan dibawa akan lebih disukai oleh anak. Hal ini yang juga kurang nampak pada mainan Warak Ngendog saat ini. Ukuran mainan yang cukup besar kurang sesuai dengan kebutuhan anak saat ini. Anak saat ini juga menyukai mainan yang lebih praktis untuk dimainkan sendiri maupun dengan teman dan tentunya mudah dibawa. Mainan Warak Ngendog yang ditarik untuk diarak keliling kampung tentunya kurang sesuai dengan perkembangan mainan saat ini. Model transformasi pada aspek ergonomi ini adalah meningkatkan keamanan dan kenyamanan mainan dengan mengganti bahan mainan menggunakan bahan 
yang aman, memperbaiki ukuran agar proporsional dengan kebutuhan anak, dan membuat bentuk mainan yang lebih praktis. Hal ini akan mengubah unsur material dan shape pada pemetaan ATUMICS. Bentuk mainan yang praktis yang sesuai kebutuhan anak saat ini mendorong perubahan mainan Warak Ngendog menjadi mainan yang modern baik digital maupun non digital.

\section{Aspek Interaksi}

Aspek interaksi berpengaruh pada perkembangan anak seperti interaksi berupa gerak, perubahan, suara atau bunyi, dan aroma atau bau. Aspek interaksi memacu keaktifan dan kreativitas anak dalam memainkannya. Mainan Warak Ngendog menunjukkan interaksi bentuk gerak dengan cara main yang digerakkan karena adanya roda. Namun saat ini banyak mainan Warak Ngendog yang tidak lagi dilengkapi dengan roda, sehingga aspek interaksi mainan berkurang dan cenderung tidak menarik untuk dimainkan. Model transformasi mainan Warak Ngendog pada aspek ini sangat diperlukan dan pemilihan bentuk interaksi sangat fleksibel sesuai dengan fungsi yang ingin dicapai. Aspek interaksi akan berpengaruh pada unsur technique pada pemetaan ATUMICS. Penambahan bentuk interaksi mainan akan mengubah teknik dan proses produksi mainan.

\section{Aspek Fungsi}

Aspek ini menjadi dasar utama pembuatan mainan. Aspek ini berkaitan dengan fungsi edukasi yang dimiliki oleh mainan yaitu pengetahuan, pengalaman, imajinasi, dan hiburan. Mainan Warak Ngendog yang hadir di setiap awal bulan Ramadhan tentunya selain berfungsi sebagai hiburan bagi anak juga untuk memberikan pemahaman dan pengetahuan bagi anak tentang budaya Warak Ngendog. Namun, fungsi edukasi pengetahuan ini yang rasanya belum sampai ke anak. Hal ini selain disebabkan oleh tidak diajarkan orang tua tetapi juga karena bentuk dan interaksi mainan tidak terarah ke fungsi edukasi pengetahuan. Model transformasi mainan Warak Ngendog pada aspek fungsi dapat dilakukan dengan memperkuat aspek interaksi pada mainan. Aspek fungsi mewakili unsur utility pada pemetaan ATUMICS dan pada model transformasi tetap mempertahankan fungsi edukasi pengetahuan yang dimilikinya.

Berdasarkan hasil analisis di atas dapat diketahui bahwa model transformasi pada mainan Warak Ngendog yang modern dan edukatif akan mempertahankan elemen concept, icon, dan utility pada pemetaan ATUMICS. Sedangkan elemen technique, material, dan shape cenderung akan mengalami perubahan untuk mendapatkan model mainan Warak Ngendog edukatif yang lebih estetis, ergonomis, dan interaktif sehingga disukai oleh anak. 


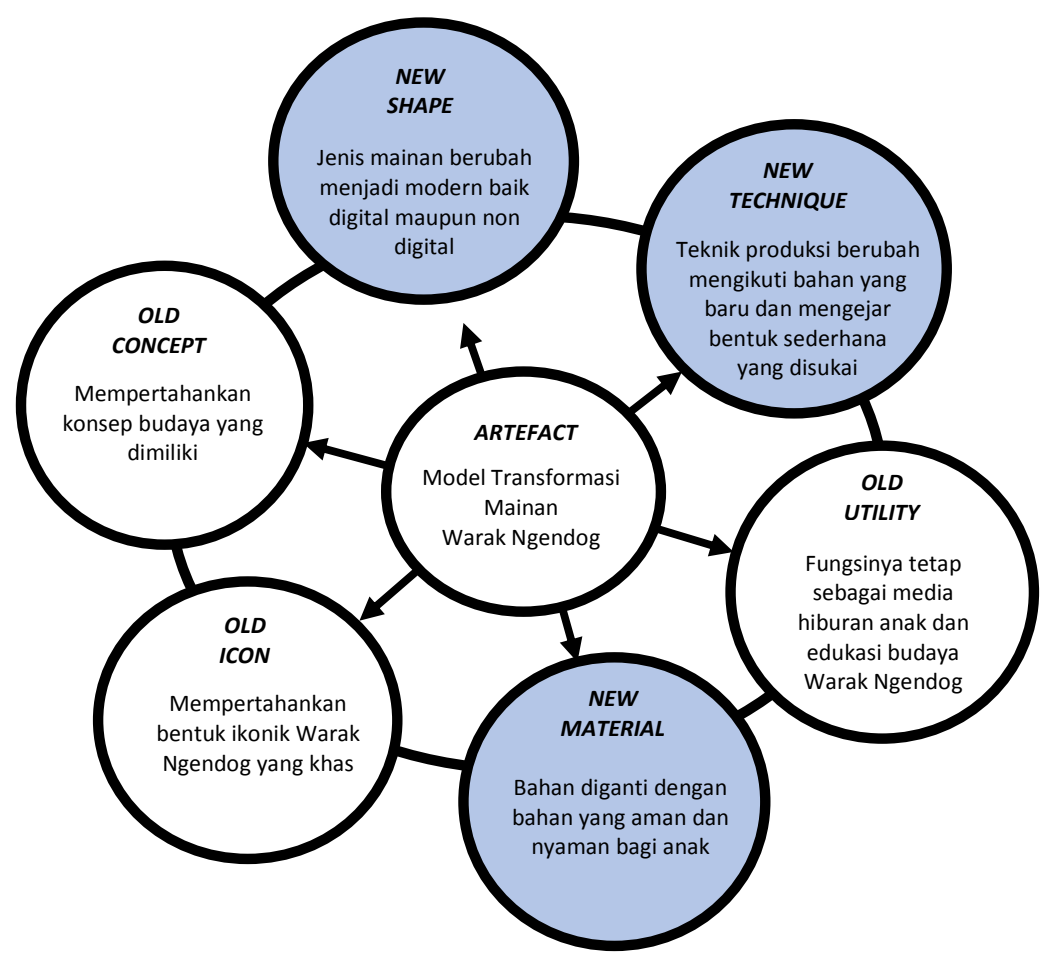

Gambar 7. Pemetaan Elemen Model Transformasi Mainan Warak Ngendog [sumber : Dokumentasi penulis]

Elemen shape menjadi dasar pengembangan bentuk mainan Warak Ngendog yang diikuti dari jenis bahan yang akan dipakai dan teknik produksi mainan tersebut. Elemen shape dapat dicontohkan dengan mengembangkan mainan Warak ngendok ke dalam jenis mainan modern non digital berbentuk action figure, model kit, dan mainan digital seperti dalam bentuk mainan robot dan aplikasi game.

Tabel 2. Contoh Penerapan Model Transformasi Mainan Warak Ngendog [sumber: dokumentasi penulis]

\begin{tabular}{|c|c|c|c|c|c|c|}
\hline No & $\begin{array}{l}\text { Shape } \\
\text { (jenis } \\
\text { mainan) }\end{array}$ & $\begin{array}{c}\text { Material } \\
\text { (bahan } \\
\text { mainan) }\end{array}$ & $\begin{array}{c}\text { Technique } \\
\text { (teknik } \\
\text { produksi) }\end{array}$ & $\begin{array}{c}\text { Concept } \\
\text { (nilai } \\
\text { budaya) }\end{array}$ & $\begin{array}{l}\text { Icon } \\
\text { (ikonik } \\
\text { bentuk) }\end{array}$ & $\begin{array}{c}\text { Utility } \\
\text { (fungsi - } \\
\text { interaksi) }\end{array}$ \\
\hline 1 & $\begin{array}{l}\text { Action } \\
\text { figure }\end{array}$ & $\begin{array}{l}\text { Bahan } \\
\text { yang } \\
\text { aman, } \\
\text { seperti } \\
\text { jenis } \\
\text { plastik } \\
\text { phthalate } \\
\text { dan non } \\
\text { PVC }\end{array}$ & $\begin{array}{l}\text { Produksi } \\
\text { menggunakan } \\
\text { bantuan mesin } \\
\text { untuk } \\
\text { produksi skala } \\
\text { medium - } \\
\text { besar }\end{array}$ & $\begin{array}{l}\text { Mem- } \\
\text { pertahankan } \\
\text { konsep } \\
\text { budaya yang } \\
\text { ada } \\
\text { didalamnya }\end{array}$ & $\begin{array}{l}\text { - Mem- } \\
\text { pertahankan } \\
\text { keikonikan } \\
\text { bentuk dan } \\
\text { struktur } \\
\text { visual Warak } \\
\text { Ngendog. } \\
\text { - Gestur } \\
\text { dapat } \\
\text { dikembang- } \\
\text { kan. }\end{array}$ & $\begin{array}{l}\text { - Edukasi } \\
\text { pengetahuan } \\
\text { dengan } \\
\text { interaksi } \\
\text { gerak dan } \\
\text { perubahan, } \\
\text { atau suara. } \\
\text { - mengembang } \\
\text { kan imajinasi }\end{array}$ \\
\hline
\end{tabular}




\begin{tabular}{|c|c|c|c|c|c|c|}
\hline 2 & $\begin{array}{l}\text { Model } \\
\text { Kit }\end{array}$ & $\begin{array}{l}\text { Bahan } \\
\text { yang } \\
\text { aman, } \\
\text { seperti } \\
\text { jenis } \\
\text { plastik } \\
\text { phthalate } \\
\text { dan non } \\
\text { PVC }\end{array}$ & $\begin{array}{l}\text { Produksi } \\
\text { menggunakan } \\
\text { bantuan mesin } \\
\text { untuk } \\
\text { produksi skala } \\
\text { medium - } \\
\text { besar }\end{array}$ & $\begin{array}{l}\text { Mem- } \\
\text { pertahankan } \\
\text { konsep } \\
\text { budaya yang } \\
\text { ada } \\
\text { didalamnya }\end{array}$ & $\begin{array}{l}\text { - Mem- } \\
\text { pertahankan } \\
\text { keikonikan } \\
\text { bentuk dan } \\
\text { struktur } \\
\text { visual Warak } \\
\text { Ngendog. } \\
\text { - Gestur } \\
\text { dapat } \\
\text { dikembang- } \\
\text { kan. }\end{array}$ & $\begin{array}{l}\text { - Edukasi } \\
\text { pengetahuan } \\
\text { dengan } \\
\text { interaksi } \\
\text { gerak dan } \\
\text { perubahan, } \\
\\
\text { - mengembang } \\
\text { kan imajinasi }\end{array}$ \\
\hline 3 & $\begin{array}{l}\text { Mainan } \\
\text { robot }\end{array}$ & $\begin{array}{l}\text { Bahan } \\
\text { yang } \\
\text { aman, } \\
\text { seperti } \\
\text { jenis } \\
\text { plastik } \\
\text { phthalate } \\
\text { dan non } \\
\text { PVC }\end{array}$ & $\begin{array}{l}\text { Produksi } \\
\text { menggunakan } \\
\text { bantuan mesin } \\
\text { dan teknologi } \\
\text { untuk } \\
\text { produksi skala } \\
\text { medium - } \\
\text { besar }\end{array}$ & $\begin{array}{l}\text { Mem- } \\
\text { pertahankan } \\
\text { konsep } \\
\text { budaya yang } \\
\text { ada } \\
\text { didalamnya }\end{array}$ & $\begin{array}{l}\text { - Mem- } \\
\text { pertahankan } \\
\text { keikonikan } \\
\text { bentuk dan } \\
\text { struktur } \\
\text { visual Warak } \\
\text { Ngendog. } \\
\text { - Gestur } \\
\text { dapat } \\
\text { dikembang- } \\
\text { kan. }\end{array}$ & $\begin{array}{l}\text { - Edukasi } \\
\text { pengetahuan } \\
\text { dengan } \\
\text { interaksi } \\
\text { gerak dan } \\
\text { perubahan, } \\
\text { atau suara. } \\
\text { - mengembang } \\
\text { kan imajinasi }\end{array}$ \\
\hline 4 & $\begin{array}{l}\text { Aplikasi } \\
\text { Game }\end{array}$ & $\begin{array}{l}\text { Media } \\
\text { mainan } \\
\text { digital } \\
\text { seperti } \\
\text { gadget, } \\
\text { smart- } \\
\text { phone }\end{array}$ & $\begin{array}{l}\text { Produksi } \\
\text { dengan } \\
\text { teknologi } \\
\text { digital, coding, } \\
\text { dan animasi }\end{array}$ & $\begin{array}{l}\text { Mem- } \\
\text { pertahankan } \\
\text { konsep } \\
\text { budaya yang } \\
\text { ada } \\
\text { didalamnya }\end{array}$ & $\begin{array}{l}\text { - Mem- } \\
\text { pertahankan } \\
\text { keikonikan } \\
\text { bentuk dan } \\
\text { struktur } \\
\text { visual Warak } \\
\text { Ngendog. } \\
\text { - Konten } \\
\text { dapat } \\
\text { dikembang- } \\
\text { kan dalam } \\
\text { sebuah } \\
\text { cerita. }\end{array}$ & $\begin{array}{l}\text { - Edukasi } \\
\text { pengetahuan } \\
\text { dengan } \\
\text { interaksi } \\
\text { gerak dan } \\
\text { suara. } \\
\text { - mengembang } \\
\text { kan } \\
\text { pengalaman }\end{array}$ \\
\hline
\end{tabular}

\section{KESIMPULAN}

Mainan Warak Ngendog dalam perkembangannya telah mengalami transformasi secara bentuk dan struktur visualnya tetapi belum sampai pada transformasi sebagai mainan yang modern. Mainan modern cenderung mudah diakses dibanding mainan Warak Ngendog yang hanya muncul di acara Dugderan. Transformasi bentuk yang ada saat ini hanya sebatas bentuk mainan yang dibuat lebih sederhana tetapi tidak mengejar produksi mainan yang modern dengan menggunakan bahan yang berbeda dan teknik produksi yang lebih efektif. Hal ini didasari oleh permintaan mainan yang hanya di waktu tertentu saja, sehingga pengrajin mainan yang sebagian besar memiliki latar belakang keahlian sebagai tukang kayu tidak memiliki semangat berinovasi. 
Transformasi yang dilakukan ini ditujukan agar mainan Warak Ngendog dapat dibuat dan dijual tanpa mengenal acara waktu tertentu sehingga proses pelestarian budaya akan berlangsung kontinu bukan sementara. Model transformasi melalui metode ATUMICS menunjukkan bahwa mainan modern yang dapat dikembangkan dari mainan Warak Ngendog masih dapat mempertahankan elemen utility, concept, dan icon-nya. Hal ini berarti nilai budaya yang bersifat intangible tetap menjadi roh mainan dengan mempertahankan struktur bentuk utama mainan yang ikonik seperti bentuk kepala, badan, dan kaki. Fungsi sebagai mainan edukasi harus tetap dipertahankan, tetapi dapat bersifat fleksibel dalam aspek bentuk interaksi mainan yang dibuat. Sedangkan elemen yang dapat berubah adalah elemen shape, material, dan technique. Mainan Warak Ngendog menjadi mainan modern yang lebih sederhana dan disukai baik dalam bentuk digital maupun non digital. Mainan Warak Ngendog dapat menjadi mainan berbentuk action figure, model kit, mainan robot, dan mainan digital seperti dalam bentuk aplikasi game. Setiap jenis bentuk mainan tersebut memiliki jenis bahan materi yang berbeda dari bahan yang ada di mainan tradisional Warak Ngendog. Bahan yang baru juga menuntut teknik produksi yang baru pula.

Akhirnya, mainan Warak Ngendog dapat dikembangkan dengan mentransformasikannya ke dalam jenis mainan modern yang disukai anak saat ini dengan menggunakan bahan materi yang baru dan aman bagi anak serta menggunakan teknik produksi yang lebih sederhana. Melalui peningkatan bentuk interaksi pada mainan yang berdasar pada fungsi edukasi pengetahuan maka pelestarian mainan Warak Ngendog dapat berjalan lebih optimal.

\section{PENGHARGAAN}

Apresiasi setinggi-tingginya diberikan kepada Kementrian Riset, Teknologi dan Pendidikan Tinggi Indonesia yang telah memberikan dukungan penuh berupa dana penelitian dosen pemula tahun 2018.

\section{DAFTAR PUSTAKA}

Hakim, F. N. 2012. Karya Komunikasi Visual dalam Dialektika Budaya Masyarakat di Kota Semarang. Jurnal Teknologi Informasi Dan Komunikasi, 3(1).

Hardiman, F. B. 2003. Melampaui Positivisme dan Modernitas: Diskursus Filosofis Tentang Metode Ilmiah dan Problem Modernitas. Yogyakarta: Kanisius.

Muliawan, J. U. 2009. Tips Jitu Memilih Mainan Positif \& Kreatif untuk Anak Anda. Yogjakarta: DIVA Press.

Nugraha, A. 2012. Transforming Tradition : a Method for Maintaining Tradition in a Craft and Design Context. Helsinki: Aalto University, School of Arts, Design and Architecture.

Nugrahastuti, E., Pupitaningtyas, E., Puspitasari, M., \& Salimi, M. 2016. Nilai-nilai Karakter pada Permainan Tradisional. In Prosiding Seminar Nasional Inovasi Pendidikan. Surakarta: Universitas Negeri Sebelas Maret.

Nurjanah, S. U. 2012. Permainan Tradisinonal: Mampukah Bertahan Di tengah Modernisasi?

Santrock, J. W. 2003. Adolescence Perkembangan Remaja (6th ed.). Jakarta: Erlangga. 
Senoprabowo, A. 2013. Perancangan Game Warak Ngendog untuk Menanamkan NilaiNilai Spiritual kepada Anak Sekolah Dasar. Institut Teknologi Bandung.

Sugiyono, S. 2012. Memahami Penelitian Kualitatif. Bandung: Alfa Beta.

Sujarno, S. 2011. Permainan Tradisional sebagai Jembatan Pembentukan Karakter Bangsa. Jantra, 6(12).

Supramono. 2007. Makna Warak Ngendog Dalam Tradisi Ritual Dugderan di Kota Semarang. Universitas Negeri Semarang.

Susanto, B. 2017. Jelang Dugderan, Sampai Lemas Perajin Patung Warak Ngendok Kerjakan Pesanan - Tribun Jateng. Retrieved August 21, 2018, from http://jateng.tribunnews.com/2017/05/11/jelang-dugderan-sampai-lemasperajin-patung-warak-ngendok-kerjakan-pesanan

Suyanto, B., \& Sutinah. 2013. Metode Penelitian Sosial: Berbagai Alternatif Pendekatan (3rd ed.). Jakarta: Prenada Media Group.

Triyanto, T., Rokhmat, N., \& Triyanto, M. 2013. Warak Ngendog : Simbol Akulturasi Budaya pada Karya Seni Rupa. Komunitas : International Journal of Indonesian Society Culture, 5(2).

Wicaksono, B. A., \& Royanto, D. 2017. Makhluk Berkaki Empat Nyaris Punah di Tradisi Dugderan. VIVA.Co.Id. 